\title{
Tunneling current via dislocations in Schottky diodes on AlInN/AIN/GaN heterostructures
}

\author{
Engin Arslan ${ }^{1,2,4}$, S, emsettin Altındal ${ }^{3}$, Suleyman“ $\quad$ Ozc, elik“ \\ ${ }^{3}$ and Ekmel Ozbay ${ }^{1,2}$ \\ ${ }^{1}$ Nanotechnology Research Center-NANOTAM, Department of Physics, Department of Electrical and \\ Electronics Engineering, Bilkent University, 06800 Ankara, Turkey \\ ${ }^{2}$ Nanotechnology Research Center-NANOTAM, Department of Electrical and Electronics \\ Engineering, Bilkent University, 06800 Ankara, Turkey \\ ${ }^{3}$ Department of Physics, Faculty of Science and Arts, Gazi University, Teknikokullar, 06500 Ankara, Turkey \\ E-mail: engina@ bilkent.edu.tr
}

Received 24 December 2008, in final form 3 April 2009

Published 26 May 2009

Online at stacks.iop.org/SST/24/075003

\begin{abstract}
The forward current-voltage-temperature characteristics of $(\mathrm{Ni} / \mathrm{Au})-\mathrm{Al}_{0.83} \mathrm{In}_{0.17} \mathrm{~N} / \mathrm{AlN} / \mathrm{GaN}$ heterostructures were studied in a temperature range of 80-375 K. The temperature dependences of the tunneling saturation current $\left(I_{\mathrm{t}}\right)$ and tunneling parameters $\left(E_{0}\right)$ were obtained. Weak temperature dependence of the saturation current and the absence of temperature dependence of the tunneling parameters were observed in this temperature range. The results indicate that in the temperature range of 80-375 K, the mechanism of charge transport in the $(\mathrm{Ni} / \mathrm{Au})-\mathrm{Al}_{0.83} \mathrm{In}_{0.17} \mathrm{~N} / \mathrm{AlN} / \mathrm{GaN}$ heterostructure is performed by tunneling among dislocations intersecting the space-charge region. A model is used for nonuniform tunneling along these dislocations that intersect the space-charge region. The dislocation density that was calculated from the current-voltage characteristics, according to a model of tunneling along the dislocation line, gives the value $7.4 \times 10^{8} \mathrm{~cm}^{-2}$. This value is close in magnitude to the dislocation density that was obtained from the $\mathrm{x}$-ray diffraction measurements value of $5.9 \times 10^{8} \mathrm{~cm}^{-2}$. These data show that the current flows manifest a tunneling character, even at room temperature.
\end{abstract}

(Some figures in this article are in colour only in the electronic version) 


\section{Introduction}

AlGaN/GaNhigh-electronmobilitytransistors(HEMTs)have beenstudiedextensivelyasidealcandidatesforhigh-frequency andhighpowerapplications[1-3]. However, manydifficulties arise from the lattice mismatch and polar surfaces for the commonlyusedAlGaN/GaNheterojunctions[4, 5]. Recently, the AlInN/GaN material system has become of major interest for electronic applications due to its promising electronic properties, polarization effects and high thermal stability [68]. An important feature of the $\mathrm{Al}_{1-x} \mathrm{In}_{\mathrm{x}} \mathrm{N}$ alloy is the possibility of growing epitaxial layers that are lattice

${ }^{4}$ Author to whom any correspondence should be addressed. $0268-1242 / 09 / 075003+06 \$ 30.00$

field effect transistors $[6,7,9,10]$. The substantially higher polarization-induced two-dimensional electron gas (2DEG) density, InAlN/GaNHEMTperformanceissuperiorregarding $\mathrm{AlGaN} / \mathrm{GaN}$ HEMTs [7, 10]. It is for this reason that AlInN materials hold great potential for $\mathrm{GaN}$-based optoelectronics. The performance and reliability of these devices are improved with high-quality Ohmic and Schottky contacts.

The InAlN/GaN HEMT structures are usually grown on highly lattice-mismatched substrates, such as sapphire [4, 5], $\mathrm{SiC}$ [11] or Si [12, 13]. Because of the large lattice mismatch and large difference in the thermal expansion coefficients among the $\mathrm{GaN}$ film, sapphire and $\mathrm{SiC}$ substrate, it is still difficult to obtain a high-quality GaN epilayer [11-13]. This fact causes a high level of in-plane stress and threading dislocation density (DD) generation, as grown by metalorganic chemical vapor deposition (MOCVD) in the $\mathrm{GaN}$ epitaxial layer [4, 5, 11-13]. These dislocations affect the performance reliability of the device $[3,4]$. If there exist many defects near the surface region, then the electrons can easily go through the barrier by/via defectassisted tunneling, thus greatly enhancing the tunneling probability. It is well established that the crystal quality of $\mathrm{Si}$ and $\mathrm{GaAs}$ is far superior to that of GaN. For Schottky barriers on Si and GaAs with a doping moderate concentration of $\sim 10^{16} \mathrm{~cm}^{-3}$, tunneling does not play a role in the currenttransport mechanisms. The current-transport mechanisms in devices such as metalsemiconductor (MS), metal-insulator- semiconductor (MIS) and solar cells are dependent on various parameters, such as the process of surface preparation, formation of an insulator layer between the metal and semiconductor, barrier height (BH) inhomogeneity, impurity concentration of a semiconductor, density of interface states or defects, series resistance $\left(R_{\mathrm{s}}\right)$ of a device, device temperature and bias voltage. In these devices, different carrier transport mechanisms may dominate the others at a certain temperature and at voltage regions, such as thermionic emission (TE), thermionic-field emission (TFE) and field emission (FE). On the other hand, a simultaneous contribution from two or more mechanisms could also be possible. TFE is important at low temperatures and high doping concentration levels. Recently, experimental results have been shown for MS, MIS and solar cells [14-18]. Among them, Kar et al [14] and Cao et al [15] presented very interesting studies, where the results indicated matched to $\mathrm{GaN}$ at an indium content $x$ of approximately $17 \%$ [7]. At the lattice-matched $\operatorname{In}_{0.17} \mathrm{Al}_{0.83} \mathrm{~N} / \mathrm{GaN}$, the heterostructureinterfaceminimizesstrain, therebyminimizing cracking and/or dislocation formation [9, 10]. In addition, at ambient pressure, it allows for the minimization of the piezoelectric polarization that is present in strained systems. However, there is still considerable spontaneous polarization, which is characteristic for nitrides crystallizing in wurtzite structures [9]. Another advantage of using AlInN barriers is their large energy band gap, which together with good mobility properties and low sheet resistance allows for the realization of structures with high electron gas densities, such as high electron mobility transistors $[7,10]$ and heterojunction

(C) 2009 IOP Publishing Ltd Printed in the UK

the likelihood of a primary currenttransport mechanism to be multistep tunneling and defectassisted tunneling instead of TE, respectively. Evstropov et al $[16,17]$ and Balyaev et al [18] showed that the current flow in the III-V heterojunctions is generally governed by multistep tunneling with the involvement of dislocations even at room temperature. They demonstrated that an excess tunnel current canbeattributedtodislocations. Amodeloftunnelingthrough a space-charge region (SCR) along a dislocation line (tube) is suggested [17].

The forward-bias current-voltage $(I-V)$ characteristics at a wide temperature range enable us to understand the different aspects of the current-conduction mechanism and barrier formation. Therefore, the aim of the present study is to investigate the current-transport mechanism in the

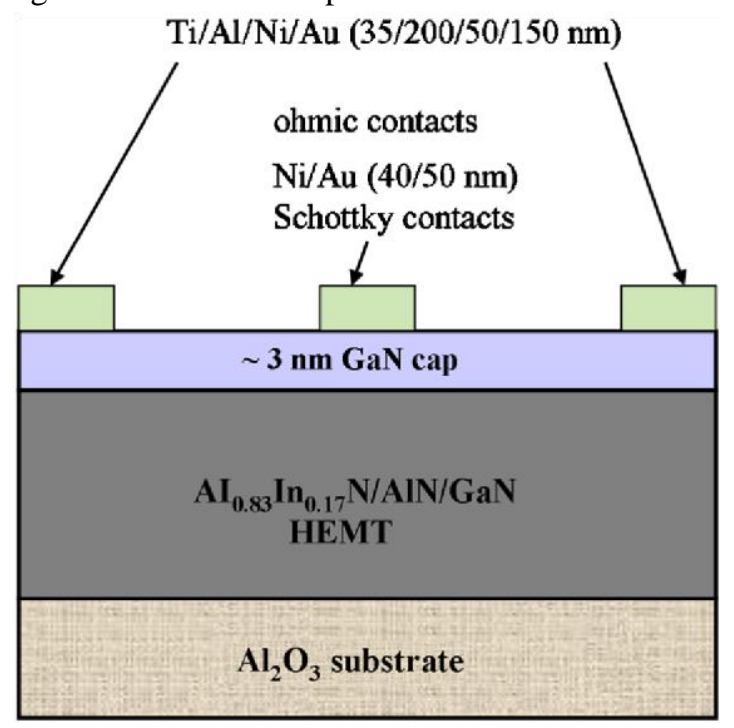

Figure 1. Schematic diagram of the (Ni/Au) $-\mathrm{Al}_{0.83} \mathrm{In}_{0.17} \mathrm{~N} /$ AlN/GaN heterostructure and view of Ohmic and Schottky contacts on the structures.

forward-biased Schottky diode on the InAlN/AlN/GaN heterostructures with a high dislocation compared with the literature in a wide temperature range (80-375 K).

\section{Experimental procedure}

The $\mathrm{Al}_{0.83} \mathrm{In}_{0.17} \mathrm{~N} / \mathrm{AlN} / \mathrm{GaN}$ heterostructure on a c-plane 
(0001) $\mathrm{Al}_{2} \mathrm{O}_{3}$ substrate was grown in a low-pressure MOCVD reactor. Prior to the epitaxial growth, the $\mathrm{Al}_{2} \mathrm{O}_{3}$ substrate was annealed at $1100{ }^{\circ} \mathrm{C}$ for $10 \mathrm{~min}$ in order to remove surface contamination. The growth was initiated with a $15 \mathrm{~nm}$ thick low-temperature $\left(840{ }^{\circ} \mathrm{C}\right)$ AlN nucleation layer. Then, a 520 $\mathrm{nm}$ high-temperature (HT) AlN buffer layer was grown at a temperature of $1150^{\circ} \mathrm{C}$. A $2100 \mathrm{~nm}$ thick undoped $\mathrm{GaN}$ buffer layer (BL) was then grown at $1070{ }^{\circ} \mathrm{C}$ and at a reactor pressure of 200 mbar. Under the GaN BL, a $2 \mathrm{~nm}$ thick HT-AlN layer was grown at $1085{ }^{\circ} \mathrm{C}$ with a pressure of 50 mbar. Then, an HT-AlN layer was followed by a $20 \mathrm{~nm}$ thick AlInN ternary layer. This layer was grown at $800{ }^{\circ} \mathrm{C}$ and at a pressure of 50 mbar. Finally, $3 \mathrm{~nm}$ thick $\mathrm{GaN}$ cap layer growth was carried out at a temperature of $1085^{\circ} \mathrm{C}$ and a pressure of 50 mbar.

The Ohmic contacts and Schottky contacts were made atop the surface as square wan de Pauw geometry and $1 \mathrm{~mm}$ diameter circular dots, respectively (figure 1). Prior to Ohmic contact formation, the samples were cleaned with acetone in an ultrasonic bath. Then, a sample was treated with boiling isopropyl alcohol for $5 \mathrm{~min}$ and rinsed in de-ionized (DI) water. After cleaning, the samples were dipped in a solution of $\mathrm{HCl} / \mathrm{H}_{2} \mathrm{O}(1: 2)$ for $30 \mathrm{~s}$ in order to remove the surface oxides and were then again rinsed in DI water for a prolonged period. For the Ohmic contact formation, Ti/Al/Ni/Au $(35 / 200 / 50 / 150 \mathrm{~nm})$ metals were thermally evaporated on the sample and were annealed at $850{ }^{\circ} \mathrm{C}$ for $30 \mathrm{~s}$ in $\mathrm{N}_{2}$ ambient. After the formation of the Ohmic contact, Ni/Au (40/50 nm) metal evaporation was done as Schottky contacts. 


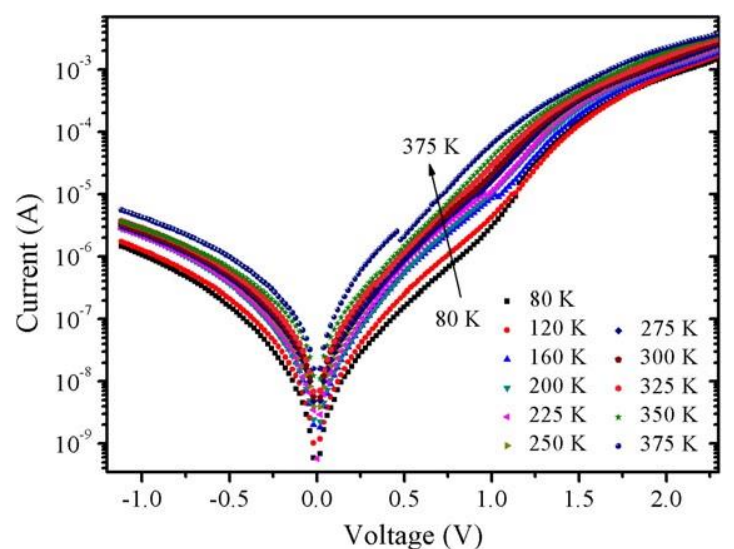

Figure 2. Experimental forward- and reverse-bias semi-logarithmic current-voltage characteristics of the (Ni/Au)-Alo.83Ino.17N/AlN/ $\mathrm{GaN}$ heterostructure.

The $I-V$ measurements were performed by the use of a Keithley 2400 source meter in a temperature range of 80-375 $\mathrm{K}$ by using a temperature-controlled Janes vpf- 475 cryostat, which enables us to make measurements in the temperature range of $77-450 \mathrm{~K}$. The sample temperature was always monitored by using a copper-constantan thermocouple close to the sample and measured with a Keithley model 199 $\mathrm{dmm} / \mathrm{scanner}$ and Lake Shore model 321 auto-tuning temperature controllers with sensitivity better than $\pm 0.1 \mathrm{~K}$. The crystalline quality (dislocation density) of the samples was examined by high-resolution x-ray diffraction (HRXRD). The X-ray diffraction was performed by using a Bruker D-8 high-resolution diffractometer system, in turn delivering $\mathrm{Cu}$ $\mathrm{K} \alpha 1(1.540 \mathrm{~A})$ radiation. $^{\circ}$

\section{Results and discussion}

Figure 2 shows a set of semi-logarithmic forward-bias $I-V$ characteristics of an $(\mathrm{Ni} / \mathrm{Au})-\mathrm{Al}_{0.83} \mathrm{In}_{0.17} \mathrm{~N} / \mathrm{AlN} / \mathrm{GaN}$ heterostructure that was measured in a temperature range of 80-375 K. As can be seen in figure 2, the forward bias of the structure current is an exponential function of the appliedbias voltage in the intermediate voltage regime $(0.1 \mathrm{~V} V \leqslant 1.4 \mathrm{~V}$ ). It is clear that between the range $10^{-7}$ and

$10^{-4} \mathrm{~A}$ of the forward current, the behavior is exponential and beyond that $\left(I 10^{-4} \mathrm{~A}\right)$ of the plots, thus deviating from this behavior. The deviation at higher current levels is mainly attributed to the series resistance $\left(R_{\mathrm{s}}\right)$ of the diode [19]. Moreover, these plots are parallel over a forward-current range of $10^{-7}-10^{-4} \mathrm{~A}$. Also, as seen in figure 2, jumps can be observed in the $I-V$ profiles at $375 \mathrm{~K}$ and $\sim 0.5 \mathrm{~V}$. These jumps can be attributed to the experimental measurements. To interpret the observed electrical characteristics of an (Ni/Au)$\mathrm{Al}_{0.83} \mathrm{In}_{0.17} \mathrm{~N} / \mathrm{AlN} / \mathrm{GaN}$ heterostructure, Riben and Feucht [20] developed a multistep recombination-tunneling model. This model successfully explains the functional dependence of the forward current on the applied voltage and temperature. Themodelassumesthatastaircasepaththatconsistsofaseries of tunneling transitions between trapping levels in the diode space-charge region coupled with a series of vertical steps

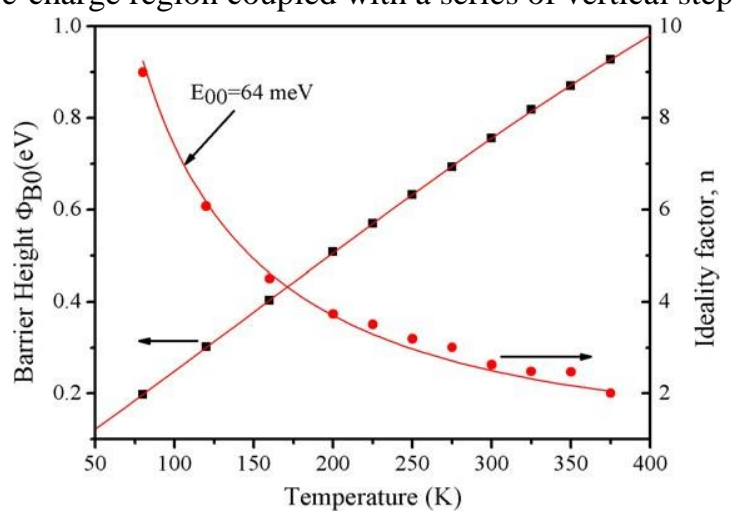

Figure 3. The zero-bias barrier height в 0 and the ideality factor $n$ of the $(\mathrm{Ni} / \mathrm{Au})-\mathrm{Al}_{0.83} \mathrm{In}_{0.17} \mathrm{~N} / \mathrm{AlN} / \mathrm{GaN}$ heterostructure obtained from the forward-bias $I-V$ data at various temperatures. The straight line is the least-squares fit of equation (5) to the $n-T$ data.

where the carrier loses energy by transferring from one level to another. However, such a process is only possible if the concentration of the trapping levels is sufficiently high. In this model, thecarriertunnelingbetweenthedefectlevelsincreases the probability of tunneling through the entire barrier.

The $I-V$ relation for a Schottky contact based on the thermionic emission theory is given by [21]

$$
I=I_{0}\left(\exp \left(\frac{q\left(V-I R_{\mathrm{s}}\right.}{n k T}\right)-1\right),
$$

where $I_{0}$ is the saturation current derived from the straight line region of the forward-bias current intercept at a zero bias and is given by

$$
I_{0}=A A^{*} T^{2} \exp \left(-\frac{q \Phi_{\mathrm{B} 0}}{k T}\right),
$$

where $\mathrm{A}$ is the contact area, $A *$ is the effective Richardson constant (55.86 $\mathrm{A} \mathrm{cm}^{-2} \mathrm{~K}^{-2}$ for undoped $\mathrm{Al}_{0.83} \mathrm{In}_{0.17} \mathrm{~N}$ ) [35], $T$ is the absolute temperature in $\mathrm{K}, q$ is the electron charge, в0 is the zero-bias apparent Schottky barrier height, $n$ is the ideality factor, $V$ is the applied bias voltage and $I R_{\mathrm{S}}$ term is the voltage drop across the series resistance $\left(R_{\mathrm{s}}\right)$ of structures.

The ideality factor $n$ is calculated from the slope of the linear region of the forward-bias $I-V$ plot and can be written, from equation (1), as

$$
n=\frac{q}{k T}\left(\frac{\mathrm{d} V}{\mathrm{~d} \ln I}\right),
$$

where $n$ is introduced to take into account the deviation of the experimental $I-V$ data from the ideal TE theory and should be $n=1$ for an ideal contact. The experimental values of в0 and $n$ weredeterminedfromequations(2)and(3), respectively, and are shown in table 1 and figure 3 . As seen in table 1 and figure 3, the values of zero-bias barrier height ${ }_{\mathrm{B} 0}$ and $n$ for the $(\mathrm{Ni} / \mathrm{Au})-\mathrm{Al}_{0.83} \mathrm{In}_{0.17} \mathrm{~N} / \mathrm{AlN} / \mathrm{GaN}$ heterostructure ranged from $0.20 \mathrm{eV}$ and 8.99 (at $80 \mathrm{~K}$ ) to $0.93 \mathrm{eV}$ and 2.0 (at $375 \mathrm{~K}$ ), 
respectively. Both parameters strongly depend on temperature. Whilendecreases, в0 increaseswithincreasing temperature. The values of во (figure 3) increase with increasing temperature, in which there is a positive coefficient that is in contrast to the negative dependence measurements by

Table 1. Temperature-dependent values of various parameters determined from the forward-bias $I-V$ characteristics of the $(\mathrm{Ni} / \mathrm{Au})-\mathrm{Al}_{0.22} \mathrm{Ga}_{0.78} \mathrm{~N} / \mathrm{AlN} / \mathrm{GaN}$ heterostructure.

\begin{tabular}{rclllll}
\hline & & Slope & & $n T$ & $E$ & $\Phi_{\mathrm{B} 0(I-V)}$ \\
$T(\mathrm{~K})$ & $I_{0}(\mathrm{nA})$ & $(\mathrm{A})\left(\mathrm{V}^{-1}\right)$ & $n$ & $(\mathrm{~K})$ & $(\mathrm{eV})$ & $(\mathrm{eV})$ \\
\hline 80 & 10 & 16.11 & 8.99 & 719.64 & 0.062 & 0.20 \\
120 & 14 & 15.91 & 6.07 & 728.92 & 0.063 & 0.30 \\
160 & 24 & 16.09 & 4.50 & 720.36 & 0.062 & 0.40 \\
200 & 28 & 15.53 & 3.73 & 746.57 & 0.064 & 0.51 \\
225 & 40 & 14.70 & 3.50 & 788.72 & 0.068 & 0.57 \\
250 & 51 & 14.53 & 3.19 & 798.00 & 0.069 & 0.63 \\
275 & 67 & 14.04 & 3.00 & 825.97 & 0.071 & 0.69 \\
300 & 81 & 14.71 & 2.63 & 788.29 & 0.068 & 0.75 \\
325 & 97 & 14.37 & 2.48 & 806.61 & 0.069 & 0.82 \\
350 & 166 & 13.42 & 2.47 & 864.21 & 0.074 & 0.87 \\
375 & 215 & 15.43 & 2.00 & 751.41 & 0.065 & 0.93 \\
\hline
\end{tabular}

Crowell and Rideout [22] in silicon Schottky diodes and Mead and Spitzer [23] in InAs and InSb, which closely follows the chargeintheforbiddenenergybandgap $\left(E_{\mathrm{g}}\right)$ withtemperature.

This contradiction is possible due to equation (2), which is not representative of the reverse saturation current of our samples implying that the current transport is not the TE.

The tunneling current through the barrier is given by [21]

$$
I_{\text {tunnel }}=I_{\mathrm{t}}\left\{\exp \left[\frac{q\left(V-I R_{\mathrm{s}}\right)}{E_{0}}\right]-1\right\}
$$

where $I_{\mathrm{t}}$ is the tunneling saturation current and $E_{0}$ is the tunneling parameter. $E_{0}$ can be defined as [20, 24, 25]

$$
\mathrm{E}_{0}=\mathrm{E}_{00} \operatorname{coth}\left(\frac{E_{00}}{k T}\right),
$$

where $E_{00}$ is the characteristic tunneling energy that is related to the tunnel effect transmission probability. It is evident that the mechanism of charge transport is a tunnel, which is indicated by the weak temperature dependence of the saturation current. For the tunneling-dominated currenttransport equation (4), the slope of the $\ln I$ versus $V$ plot $\left(q / E_{0}=q / n k T\right)$ is essentially temperature independent and is called a voltage factor or tunneling constant. In addition, at a constant bias voltage, $\ln I$ is more of a linear function of temperature than of an inverse temperature. According to the tunneling model, which was developed for Schottky barriers, the band bending works as a barrier for carriers tunneling into interface states or dislocations, where various traps may be involved in multi-tunneling steps [20]. Thermally activated carriers make (step-wise) tunneling into the interface states possible. The values of slope $\ln I$ versus $V$ plots at different temperatures with the corresponding values of the ideality factor (obtained from equation (3)) are shown in table 1 and figure 3. As can be seen in table 1 , the $n$ values change from 8.99 (at $80 \mathrm{~K}$ ) to 2.00 (at $375 \mathrm{~K}$ ). However, the slope and $n T$ values remain nearly unchanged over the same temperature range with an average of $15 \mathrm{~V}^{-1}$ and $776 \mathrm{~K}$, respectively. The high value of $n$ was attributed to several effects such as interface states, tunneling currents in the high dislocations [16-18], image force lowering of the Schottky barrier in the high electric field at an MS interface and generation currents within the space-charge region [21]. The TFE mechanism can

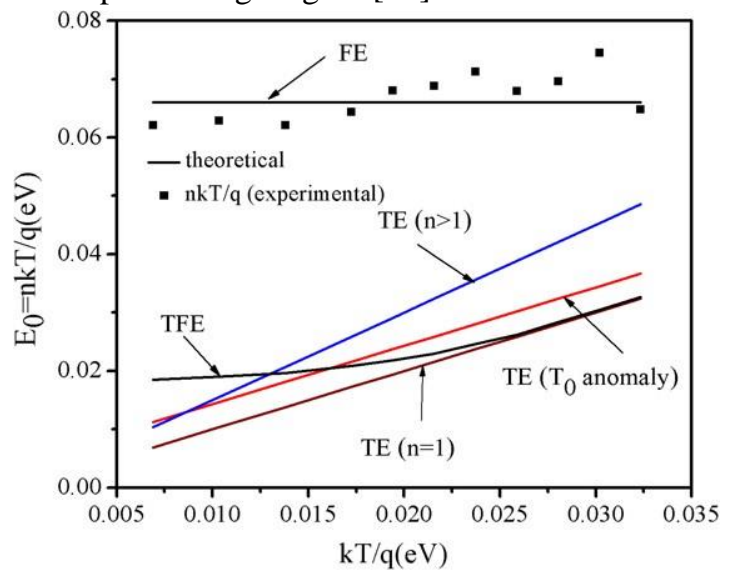

Figure 4. Experimentally and theoretically found tunneling current parameter $E_{0}(n k T / q)$ versus $k T / q$ for the $(\mathrm{Ni} / \mathrm{Au})-\mathrm{Al}_{0.83} \mathrm{In}_{0.17} \mathrm{~N} /$ AlN/GaN heterostructure.

be ruled out in this region, since $n T$ is more or less constant in the measured temperature range. Apart from discussing the main carrier transport mechanisms, the ideality factor is further analyzed by plotting $n k T / q$ against $k T / q$ as shown in figure 4, which shows the experimental and theoretical results of these plots. If FE dominates, then the $E_{0}$ data will lie on a straight line as can be seen in figure 4 . In this case, $E_{0}$ is independent of the temperature and $E_{0}$ is very close to the $E_{00}$ values [26]. In our study, the average value of $E_{0}$ was found to be $66 \mathrm{meV}$, which is very close to the $67 \mathrm{meV}$ value of $E_{00}$ that was obtained by fitting equation (5) to the $n(T)$ data (figure 3).

The temperature dependences of $I_{\mathrm{t}}$ and $E_{0}$ are shown in figure 5 . The results indicate that in the temperature range of 80-375 K, the mechanism of charge transport in the (Ni/Au)$\mathrm{Al}_{0.83} \mathrm{In}_{0.17} \mathrm{~N} / \mathrm{AlN} / \mathrm{GaN}$ heterostructure is tunneling, which is demonstrated by the weak temperature dependence of the saturation current and the absence of the temperature dependence of the tunneling parameters in this temperature range [15-18, 27-30]. The $I-V$ behavior of the tunneling current in the barrier structures fabricated based on degenerate semiconductors (Schottky diodes, $\mathrm{p}-\mathrm{n}$ heterojunctions) can be expressed by equation (4) according to the dislocation model of the tunneling current, in which the tunneling saturation current $\left(I_{\mathrm{t}}\right)$ can be represented by the equation of the form [1618] 


$$
\mathrm{I}_{\mathrm{t}}=\mathrm{qD} v_{\mathrm{D}} \exp \left(-\mathrm{q} \mathrm{V}_{\mathrm{K}} / \mathrm{E}_{0}\right)
$$

(6) We calculated the dislocation density for $(\mathrm{Ni} / \mathrm{Au})-$ $\mathrm{Al}_{0.83} \operatorname{In}_{0.17} \mathrm{~N} / \mathrm{AlN} / \mathrm{GaN}$ heterostructures by using $I_{\mathrm{t}}(0)=$

where $D$ is the dislocation density, $v_{\mathrm{D}} \approx 1.5 \times 10^{13} \mathrm{~s}^{-1}$ is the

Debye frequency for the $\mathrm{Al}_{0.83} \mathrm{I}_{0.17} \mathrm{~N}$ layer [31] and

$q V_{\mathrm{K}}=\Phi_{\mathrm{B}}-\mu_{\mathrm{n}}$ is the diffusion potential for the Schottky

barrier diode (SBD). In this equation, в is the height of the

$\mathrm{SBD}, \mu_{\mathrm{n}} \cong k T \ln \left(\frac{N_{\mathrm{C}}}{N_{\mathrm{D}}}\right)$ is the chemical potential, $N_{\mathrm{C}}$ is the effective density of states in the conduction band [21], $N_{\mathrm{D}}$ is the concentration of the ionized donors in the AlInN barrier layer and $E_{0}=n k T$ is the tunneling parameter.

By using the model equation (6), determining $I_{\mathrm{t}}$ and $E_{0}$ from the measured $I-V$ characteristic and knowing $V_{\mathrm{K}}(0)$, the

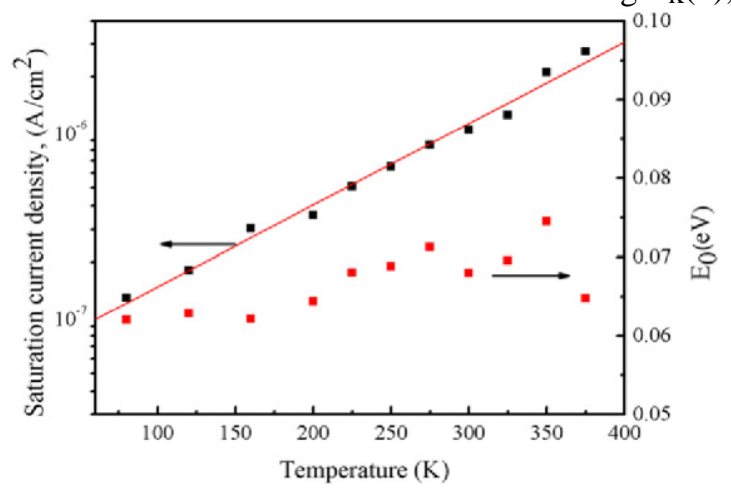

Figure 5. Temperature dependence of the tunneling saturation current $I_{\mathrm{t}}$ and tunneling parameter $E_{0}$, which calculated from the tunneling current equation fits to the measured $I-V$ data.

expression for the dislocation density can be expressed as [1618]

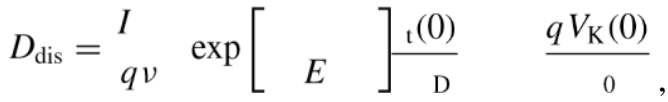

where $I_{\mathrm{t}}(0)$ and $\mathrm{E}_{0}(0)$ can be obtained by extrapolation of the absolutetemperatureoftheirtemperaturedependencestozero.

The value of $\mathrm{qV}_{\mathrm{K}}(0)$ can be calculated from the empirical dependence of ${ }_{\mathrm{B}}$ on the band gap $E_{\mathrm{g}}$ in $\mathrm{GaN}$ (because in our study, Schottky diodes were done on GaN cap layers), $\Phi_{\mathrm{B}} \approx \frac{1}{3} E_{\mathrm{g}}^{\mathrm{GaN}}[18]$,

$$
q V_{\mathrm{K}}(0)=\Phi_{\mathrm{B}}(0)-\mu_{\mathrm{n}}(0) \cong \frac{1}{3} E_{\mathrm{g}}^{\mathrm{GaN}}(0)-\mu_{\mathrm{n}}(0) .
$$

The dislocation density can be calculated by equation (7) by using $I_{\mathrm{t}}(0), \mathrm{E}_{0}(0), \mathrm{qV}_{\mathrm{K}}(0)$ and $E_{\mathrm{g}}(0)=3.47 \mathrm{eV}$ values for $\mathrm{GaN}$. In addition, this case was supported by the experimental values of the height of the Schottky barrier that was formed on the GaN layers by pure metals Ni, Pt, Ir [32] and Au [33].

$$
\begin{gathered}
\text { edge } \\
\text { Ddis }=D_{\text {screw }}+\text { Dedge, }
\end{gathered}
$$$$
1
$$

$5.31 \times 10^{-8} \mathrm{~A} \mathrm{~cm}^{-2}, \mathrm{E}_{0}(0)=60 \mathrm{meV}$ and $\mathrm{qV}_{\mathrm{K}}(0)=$

$1.15 \mathrm{eV}$ values. We obtained the dislocation density for $\mathrm{Al}_{0.83} \mathrm{In}_{0.17} \mathrm{~N} / \mathrm{AlN} / \mathrm{GaN}$ heterostructures as $7.4 \times 10^{8} \mathrm{~cm}^{-2}$.

$\mathrm{TheAl}_{0.83} \mathrm{In}_{0.17} \mathrm{~N} / \mathrm{AlN} / \mathrm{GaNheterostructuresweregrown} \mathrm{on}$ sapphire with two steps that exhibited high dislocation densities [5, 13, 36]. The dislocation density (DD) of the sample was investigated by the methods of high-resolution diffractometry. There are three main types of dislocations that are present in the GaN epitaxial layers [13, 34, 36]. Theses dislocation densities are the pure edge dislocation with the

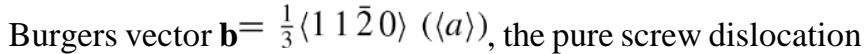
with the Burgers vector $\mathbf{b}=\langle 0001\rangle(\langle c\rangle)$ and the mixed dislocation with $\mathbf{b}=\frac{1}{3}\langle 11 \overline{2} 3\rangle(\langle\mathbf{c}+\mathbf{a}\rangle)$. The dislocation densities of $\mathrm{GaN}$ can be determined from the following equations [34]:

$$
D_{\text {screw }}=\underset{b^{2}}{(002)} \quad \beta_{2}=\frac{\beta_{(121)}^{2}}{9 b^{2}}
$$

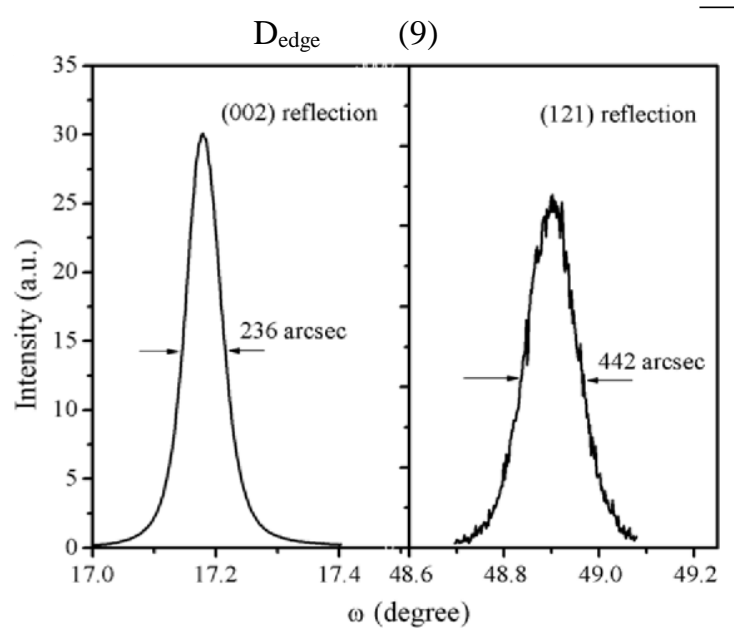

Figure 6. The x-ray rocking curves of the (002) and (121) reflections of the GaN epilayer.

(FWHM) of the measured XRD rocking curves and $b$ is the Burgersvectorlength $\left(b_{\text {screw }}=0.5185 \mathrm{~nm}, b_{\text {edge }}=0.3189 \mathrm{~nm}\right)$. The measured XRD rocking curves for (002) and (121) reflections are shown in figure 6 . The FWHM values measured for (002) and (121) reflections are 236 arcsec and 442 arcsec, respectively. By using equations $\left({ }^{1}\right)$ and (10), we can calculate the values for the screw, edge and total dislocation densities as $5.4 \times 10^{7} \mathrm{~cm}^{-2}, 5.0 \times 10^{8} \mathrm{~cm}^{-2}$ and $5.9 \times 10^{8} \mathrm{~cm}^{-2}$, respectively. These dislocation density values nearly equal the results that were calculated from those measured from the

where $D_{\text {screw }}$ is the screw dislocation density, $D_{\text {edge }}$ is the edge dislocation density, $\beta$ is the full width half-maximum 
current-transport measurements. These dislocation densities are consistent with the values given for $\mathrm{GaN}$ epitaxial films in the literature $[5,12,13,36]$. Analysis of the forward-bias $I-V$ data indicated that the predominant current mechanism of the $\mathrm{Al}_{0.83} \mathrm{In}_{0.17} \mathrm{~N} / \mathrm{AlN} / \mathrm{GaN}$ heterostructure with high dislocation densities in the intermediate-bias voltage region that was investigated in this study was a dislocation-governed currenttransport mechanism rather than other currenttransport mechanisms.

\section{Conclusion}

In conclusion, the temperature-dependent forward-bias current-voltage $(I-V)$ characteristics of the $(\mathrm{Ni} / \mathrm{Au})-$ $\mathrm{Al}_{0.83} \mathrm{In}_{0.17} \mathrm{~N} / \mathrm{AlN} / \mathrm{GaN}$ heterostructure were measured in the temperature range of $80-375 \mathrm{~K}$. The tunneling saturation current $\left(I_{\mathrm{t}}\right)$ and tunneling parameter $\left(E_{0}\right)$ were calculated from the $I-V$ measurements. The temperature dependence of the tunnel saturation current $\left(I_{\mathrm{t}}\right)$ was weak. Moreover, $E_{0}$ was nearly independent of the temperature. These results show that the charge transport mechanism in the temperature range of $80-375 \mathrm{~K}$ in the forward-biased $(\mathrm{Ni} / \mathrm{Au})$

$\mathrm{Al}_{0.83} \mathrm{In}_{0.17} \mathrm{~N} / \mathrm{AlN} / \mathrm{GaN}$ heterostructures was performed by the tunneling mechanism among the dislocations intersecting the space-charge region. The dislocation density (DD) that was calculated from the $I-V$ characteristics, according to a model of tunneling along the dislocation line, gives the value $7.4 \times$ $10^{8} \mathrm{~cm}^{-2}$. This value is very close in magnitude to the dislocationdensitythatwasobtainedfromthex-raydiffraction (XRD) measurements value $5.9 \times 10^{8} \mathrm{~cm}^{-2}$. These data show that the current flows manifest a tunneling character, even at room temperature.

\section{Acknowledgments}

This work is supported by projects EUNoEMETAMORPHOSE EU-NoE-PHOREMOST and DPT2001-

K120590, as well as by Gazi University BAP-05/2006-30 and TUBITAK under project nos. 105E066, 105A005, 106E198 and 106A017. One of the authors (EO) also acknowledges partial support from the Turkish Academy of Sciences.

\section{References}

[1] Morkoc, H 1999 Nitride Semiconductors and Devices (Heidelberg: Springer)

[2] Mohammad S N and Morkoc, H 1996 Prog. Quantum Electron. 20361

[3] Biyikli N, Aytur O, Kimukin I, Tut T and Ozbay E 2002 Appl. Phys. Lett. 813272

[4] Arslan E, But" un S, Lisesivdin S B, Kasap M, Ozcelik S“ and Ozbay E 2008 J. Appl. Phys. 103103701

[5] Yu H, Caliskan D and Ozbay E 2006 J. Appl. Phys. 100 033501
[6] Katz O, Mistele D, Meyler B, Bahir G and Salzman J 2005 IEEE Trans. Electron Devices 52146

[7] Gonschorek M, Carlin J-F, Feltin E, Py M A and Grandjean N 2006 Appl. Phys. Lett. 89062106

[8] Gadanecz A, Blasing J, Dadgar A, Hums C and Krost A 2007" Appl. Phys. Lett. 90221906

[9] Katzer D S, Storm D F, Binari S C, Shanabrook B V, Torabi A, Zhou L and Smith D J 2005 J. Vac. Sci. Technol. B 23 1204

[10] Kuzm'1k J, Kostopoulos A, Konstantinidis G, Carlin J-F, Georgakilas A and Pogany D 2006 IEEE Trans. Electron Devices $\mathbf{5 3} 422$

[11] Gaska R, Yang J W, Osinsky A, Chen Q, Khan M A, Orlov A O, Snider G L and Shur M S 1998 Appl. Phys. Lett. 72707

[12] Dadgar A, Hums C, Diez A, Blasing J, Krost A and Cryst J“ 2006 Growth 297279

[13] Arslan E, Ozturk M K, Teke A, Ozcelik S and Ozbay E 2008 J. Phys. D: Appl. Phys. 41155317

[14] Kar S, Panchal K M, Bhattacharya S and Varma S 1982 IEEE Trans. Electron Devices 291839

[15] Cao X A, LeBoeuf S F, Kim K H, Sandvik P M, Stokes E B, Ebong A, Walker D, Kretchmer J, Lin J Y and Jiang H X 2002 Solid-State Electron. 462291

[16] Evstropov V V, Zhilyaev Yu V, Dzhumaeva M and Nazarov N 1997 Fiz. Tekh. Poluprovodn. 31152

Evstropov V V, Zhilyaev Yu V, Dzhumaeva M and Nazarov N 1997 Semiconductors 31115

[17] Evstropov V V, Dzhumaeva M, Zhilyaev Yu V, Nazarov N, Sitnikova A A and Fedorov L M 2000 Fiz. Tekh. Poluprovodn. 341357

Evstropov V V, Dzhumaeva M, Zhilyaev Yu V, Nazarov N, Sitnikova A A and Fedorov L M 2000 Semiconductors 341305

[18] Belyaev A E, Boltovets N S, Ivanov V N, Kladko V P, Konakova R V, Kudrik Ya Ya, Kuchuk A V, Milenin V V, Sveshnikov Yu N and Sheremet V N 2008 Semiconductors 42689

[19] Chand S and Bala S 2005 Semicond. Appl. Surf. Sci. 252358 [20] Riben A R and Feucht D L 1966 Int. J. Electron. 20583 [21] Sze S M 1981 Physics of Semiconductor Devices (New York: Wiley)

[22] Crowell C R and Rideout V L 1969 Solid-State Electron. 1289

[23] Mead C A and Spitzer W G 1964 Phys. Rev. 134 A713 [24] Donoval D, Barus M and Zdimal M 1991 Solid-State Electron. 341365

[25] Bayhan H and Sertap Kavasoglu A 2005` Solid-State Electron. 49991

[26] Yu A Y C and Snow E H 1968 J. Appl. Phys. 393008

[27] Marchand J J and Truong K 1983 J. Appl. Phys. 547034

[28] Ozdemir S and As,tindal S, 1994" Sol. Energy Mater. Sol. Cells 32115

[29] Ashok S, Sharma P P and Fonash S J 1980 IEEE Trans. Electron Devices ED-27 725

[30] Saxena A N 1969 Surf. Sci. 13151

[31] Morkoc Hadis 2008 Handbook of Nitride Semiconductors and Devices: Volume 1: Materials Properties, Physics and Growth (New York: Wiley-VCH) 
[32] Kumar V, Selvanathan D, Kuliev A, Kim S, Flynn J and Adesida I 2003 Electron. Lett. 39747

[33] Monroy E et al 2002 Semicond. Sci. Technol. 17 L47

[34] Metzger T et al 1998 Phil. Mag. A 771013

[35] Levinshtein M, Rumyantsev S L and Shur M S 2001 Properties of Advanced Semiconductor Materials (New York: Wiley) [36] Arslan E, Altındal S, Ozc, elik S and Ozbay E 2009“ J. Appl. Phys. 105023705 